\title{
A STUDY OF VARIABILITY \\ IN BOTRYTIS
}

\section{$\mathrm{By}$}

CARLOS ENRIQUE AMPUERO

\begin{abstract}
A DISSERTATION PRESENTED TO THE GRADUATE COUNCIL OF THE UNIVERSITY OF FLORIDA

IN PARTIAL FULFILLMENT OF THE REQUIREMENTS FOR THE DEGREE OF DOCTOR OF PHILOSOPHY
\end{abstract}

UNIVERSITY OF FLORIDA

August, 1965 
TO DORA

AND

ANA 


\section{ACKNOWLEDGMENTS}

The author wishes to express his deep appreciation to Dr. Allyn A. Cook, chairman of the advisory committee, for suggesting the problem, advice during the course of the research and assistance in preparing the manuscript. He is also indebted to the members of his committee: Dr. D. A. Roberts, Dr. H. H. Luke, Dr. S. C. Schank and Dr. D. S. Anthony for their invaluable suggestions in the preparation of this manuscript. Thanks are also due to Dr. P. Decker, Head of the Plant Pathology Department, for the assistance offered in carrying on this work, and to Dr. H. N. Miller, for permitting the use of some laboratory facilities. Gratitude is expressed to the United States Agency for International Development for providing the scholarship which made possible the graduate studies of the author and to the National Institute of Agriculture Research of Ecuador for financial support. Special thanks to Mrs. Dora Ampuero for her understanding, encouragement, and assistance during this period. 
TABLE OF CONTENTS

Page

ACKNOWLEDGMENTS .................. 1 ...

LIST OF TABLES .................... . . . v

LIST OF FIGURES !..................... . . . vi

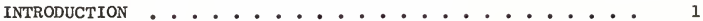

MATERIALS AND METHODS ................. 5

Fungus Cultures ................. 5

Media.................... 5

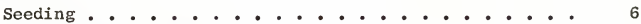

Paramorphogenic Agents ............. 6

Antibiotics .................. . . . 7

Isolation of Selected Clones .......... 8

Pathogenicity Tests .............. . . 9

Carbon Sources ............... . . 10

Mycelial Inhibition ................ 11

RESULTS .................... . . 12

Influence of Paramorphogenic Agents . . . . . . . 12

Inhibition of Botrytis Species by Antibiotics . . . . 15

Pathogenicity Tests............. 20

Effect of Carbon Source on Growth of Selected Clones . 24

Influence of Carbon Source on Antibiotic Inhibition of

Mycelial Growth ............ 26

DISCUSSION ........................ 31

SUMMARY . . . . . . . . . . . . . . 39

LITERATURE CITED . . . . . . . . . . . . . 41

BIOGRAPHICAL SKETCH ............... . . 48 


\section{LIST OF TABLES}

Table

Page

1. Effect of three paramorphogenic agents on colony formation of three Botrytis species . . . . . .

2. Concentration of five antibiotics required to inhibit mycelial growth of three Botrytis species (three experiments, each of four weeks' incubation) ....

3. Pathogenicity of eight Botrytis isolates on pepper seedlings (var. California Wonder), January-March, 1964

4. Pathogenicity of eight clones of B. cinerea (pepper isolate) selected on nystatin medium (200 units/ml)

5. Pathogenicity of 22 clones of $B_{0}$ cinerea isolated on

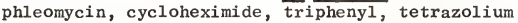
chloride, and sodium dodecyl sulfate media, JanuaryMarch, 1965 ...............

6. Average dry weight (mg) of mycelial growth per flask of three Botrytis isolates on liquid media with 12 different carbon sources ............

7. Weight (mg) of dried mycelium per flask produced by 13 clones of B. cinerea (pepper isolate) grown in liquid media with four carbon sources after nine days' incubation..............

8. Influence of three carbon sources on phleomycin $(6,000$ ppm) inhibition of mycelial growth of B. cinerea after 96 hours' incubation ..........

9. Influence of three carbon sources on nystatin $(1,000$ units $/ \mathrm{ml}$ ) inhibition of mycelial growth of $\mathrm{B}$. cinerea after 96 hours' incubation .... 
1. Paramorphogenic effect of sodium desoxycholate, L-sorbose, and dodecyl sodium sulfate on $B$. cinerea (C. annuum isolate) left column, $\bar{B}$. gladiolorum middle column, and $B_{\text {. }}$ allii, right column, after 5-7 days. A, B, C) Control; D, E, F) $0.03 \%$ sodium desoxycholate; G, H, I) $0.1 \%$ L-sorbose; J, K, L) $0.008 \%$ dodecyl sodium sulfate. Appr. $1.0 \mathrm{x}$..............

2. Average inhibition of three Botrytis species by nystatin and phleomycin - modified paper disc technique (Areas covered by paper discs subtracted from inhibition zones)...............

3. Antibiotic inhibition of $B$. cinerea (type isolate from pepper) mycelial growth, using paper disc technique; (A, 1-4) phleomycin, 2000, 3,500, 5,000 ppm and control, respectively; (B, 1-4) nystatin, 200, 500, 800 units/ $\mathrm{ml}$ and control, respectively. After 4 days'incubation. Appr. 1.0 x............. 


\section{INTRODUCTION}

One of the major concerns of plant pathologists is the loss of pathogenicity of fungi maintained in vitro (15). Instability becomes apparent when a fungus is transferred from a parasitic environment (in vivo) to a saprophytic condition (in vitro). Such a change of environment may serve to favor non-pathogenic biotypes included in the heterogeneous population of biotypes that constitute the species as defined. Variant forms better adapted to a saprophytic existence are favored by continued selection pressures in vitro, and the pathogenic biotypes are gradually overgrown and replaced.

Variability has been attributed to high mutability $(16,78)$; heterokaryosis $(10,13,37,39,42,62)$; saltation $(27,47)$; adaptation (14, 18, 19); and parasexualism, initially described by Pontecorvo $(65,66)$. Buxton (13) attributed the variability of Fusarium oxysporum to the latter process, although Snyder (78) believed mutation to be more important. Likewise, Gabrielson (36) presumed mutation to be the cause of sectors in Septoria apiicola.

Hansen (38) explained part of the variability observed in 29 genera and 35 species of imperfect fungi as due to heterokaryosis and indicated that a dual phenomenon was common in Botrytis and other imperfect fungi. In such organisms, a single spore may give rise to three cultural types: one producing abundant mycelia and few conidia, another producing many conidia and relatively less mycelia, and a third type, in general, intermediate between the other two types. Hansen concluded that individual 
cells and spores of such fungi contained two genetically distinct types of nuclei, but that the change from conidial to mycelial type was due to mutation $(40)$.

For sexually reproducing plant pathogens, hybridization is the most probable method for creating variant biotypes $(31,33,46,81,89,90,91)$. The literature concerning variation in phytopathogenic fungi has been extensively reviewed $(10,17,22,31,43,70,77,80)$.

Lack of adequate techniques to differentiate plant pathogenic biotypes in vitro has prevented elucidation of the basic variability in pathogenicity. The criteria frequently followed to characterize "variants" have been based mainly on gross morphology, growth rate, and pathogenicity $(37,38,60)$. Distinctions among cultural types based on morphological characters is questionable because of the temporary influence of nutritional and environmental factors $(56,76)$. Physiological responses would be more reliable criteria to distinguish biotypes. Some of the techniques developed for the study of bacteria and non-phytopathogenic fungi $(1,6,21,35,51$, $52,53,54,59,64,71,83,93)$, conceivably could be modified to study variability in phytopathogens.

A technique described by Tatum et a1. (83) could be applied to facilitate the selection of plant pathogenic biotypes. Restricted growth of colonies was induced in Neurospora and Syncephalastrum using L-sorbose or sodium desoxycholate as well as other surface active agents added to a synthetic media. These authors proposed the term "paramorphic" to designate a fungus culture in which morphological changes have been environmentally induced without any corresponding genetic alteration. 
The influence of paramorphogenic agents has been determined only for saprophytic fungi. This technique could be adapted to facilitate the selection of biotypes and assist in assessment of inherent genetic variation of phytopathogens in vitro as well as in vivo. Ampuero et al. (2) studied the response of 12 plant pathogenic fungi to L-sorbose and sodium desoxycholate. Both paramorphogens restricted the colony growth of nine fungi each, and sodium desoxycholate completely inhibited colony formation of Phomopsis vexans, $\underline{P} \cdot \underline{\text { citri }}$ and Monilia fructicola.

Recently some investigators have attempted to use more precise techniques to differentiate pathogenic biotypes $(34,41,49,74,88)$. The use of specific amendments in culture media would be more reliable criteria to select desired biotypes from a heterogeneous population of biotypes that constitute many individual phytopathogens. The selective media should not produce a drastic change in the pathogen as is the case when mutagenic agents are employed $(5,7,30,32,48,50)$.

Clones could be selected from a heterogeneous population of phytopathogens using antibiotics or other appropriate amendments in culture media. Antibiotics have been utilized to isolate bacteria and fungi from soil $(44,61,86)$, in isolation from diseased or decayed plant parts (28, 72), selection of auxotropic mutants in yeast (59), inhibition of phytopathogenic bacteria in vitro (45), and control of plant diseases (23). The group of imperfect fungi seems well adapted to a study of the inherent asexual genetic variation of phytopathogens, because a sexual stage does not contribute to cultural instability. Much of the information available on variation within this group of $f$ ungi has been carried out with non-phytopathogenic types $(58,66,67)$, although other genera, 
i.e, Botrytis, would be suitable subject material. Brierley (10) visualized B. cinerea as a "cluster of numerous races or strains morphologically congruent in the host but in vitro showing marked and constant cultural differences." Species of this genus would be particularly well adapted because a) they are easy to grow in culture, b) isolates pathogenic on a wide range of plants can be obtained, c) they are known to be an unstable group of fungi $(11,63)$, in which the taxonomy is not well elucidated (82), and d) the conidia are one-celled but multinucleate (37). The objective of the research reported herein was to develop and adapt techniques which could be applied to assess in vitro as well as in vivo the inherent variability of some Botrytis species. 
MATERIALS AND METHODS

\section{Fungus Cultures}

The original isolates of Botrytis used in this study were obtained as follows: Botrytis cinerea Fr.: a) isolated from infected flowers of pepper grown at Gainesville, Florida; b) isolated from diseased chrysanthemum plant material received from Fort Nyers, Florida; c) isolated from tomato and received from the Indian River Experimental Station, Ft. Pierce, Florida; d, e, f) cultures isolated from strawberry, African violet, and kenaf, respectively, received from Everglades Experimental Station, Belle Glade, Florida. Botrytis allii Munn: isolated from an infected onion bulb collected in Gainesville, Florida; Botrytis gladiolorum Timm.: isolated from infected gladiolus flowers received from Gulf Coast Experimental Station, Bradenton, Florida.

Media

A basic synthetic medium of the following composition was used throughout these experiments: $\mathrm{KCl}-0.1 \%, \mathrm{KH}_{2} \mathrm{PO}_{4}-0.15 \%, \mathrm{NaNO}_{3}-0.3 \%, \mathrm{MgSO}_{4}-0.05 \%$, casein hydrolysate- $0.3 \%$, yeast extract $-0.3 \%$, glycerol-0.1\%, agar-2.0\% in 1,000 $\mathrm{mI}$ of water. The medium was amended before steam sterilization with either L-sorbose or sodium desoxycholate. Stock solutions of sodium dodecyl sulfate and hexachlorocyclohexane were sterilized by filtration and added to the basic medium after sterilization. In the same manner, sterile stock solutions of the antibiotics were prepared and samples, to give the desired concentration, added to the medium after sterilization. 


\section{$\underline{\text { Seeding }}$}

The sterilized media in petri plates were seeded by placing a drop (appr. $0.05 \mathrm{ml}$ ) of a spore suspension on the agar when isolation of single colonies was intended or five drops (appr. $0.25 \mathrm{ml}$ ) when inhibition to antibiotics was being determined. The spores were then spread evenly over the surface of the modium with a sterile glass rod. A small amount of polyoxyethylene sorbitan monolaurate (Tween 20) was added to the suspensions to facilitate dispersion of spores. All cultures were seeded inside a sterile chamber after which the petri cultures were incubated at $75 \pm 5^{\circ} \mathrm{F}$.

\section{Paramorphogenic Agents}

The following materials were assayed for paramorphogenic activity: a) L-sorbose (Matheson, Coleman and Bell); b) sodium desoxycholate (Nutritional Biochemicals Corporation); c) dodecyl sodium sulfate (Matheson, Coleman and Bel1); and d) 1-2-3-4-5-6 hexachlorocyclohexane (Eastman Organic Chemicals). The first two of these were added to the media before steam sterilization to obtain the following concentrations: L-sorbose, $0.1,1.0,2.0,3.0$, or $4 \%$; sodium desoxycholate $0.03,0.05,0.07,0.1$, 0.2 , or $0.3 \%$. Dodecycl sodium sulfate and hexachlorocyclohexane were added to the media after sterilization to give concentrations of 0.006 , 0.008 and $0.01 \%$ and $0.03,0.05,0.07$ or $0.1 \%$, respectively. Each treatment consisted of 10 petri culture replicates. Control cultures on the basic medium were included in all experiments. 


\section{Antibiotics}

Five antibiotics, supplied by the commercial companies mentioned below, were used: a) nystatin (Mycostatin, E. R. Squibb and Sons), b) phleomycin (Dowco 189, Dow Chemical Corp.), c) cycloheximide (Actidione, Upjohn Co.), d) griseofulvin (Schering Corp.), and e) pimaracin (Pimafucin, Mycofarm-Delft, Holland).

Stock solutions of the antibiotics were sterilized by filtration through Seitz-filters of 1 micron nominal pore-diameter and appropriate quantities added to sterilized media. Ranges of concentrations from 0.1 to $700 \mathrm{ppm}$ of cycloheximide, griseofulvin, or pimaracin and 0.1 to 30 ppm of phleomycin, were assayed to determine inhibition of three Botrytis species. Nystatin was assayed in concentrations of 10 to 400 units/ml of media. (Units of nystatin were calculated from the descriptive literature received from E.R. Squibb and Sons.)

For selection of clones tolerant to antibiotics, either $0.03 \%$ sodium desoxycholate or $1.0 \% \mathrm{~L}$-sorbose was added to the medium to induce restricted growth of colonies. In experiments to determine possible inhibition of Botrytis species by antibiotics, no paramorphogenic agents were added to the basic medium.

Inhibition of Botrytis species with antibiotics was also studied using a modification of the paper disc technique described by Loo et al. (57). Twenty $\mathrm{ml}$ of sterile basic medium were delivered into petri dishes (about $100 \mathrm{~mm}$ in diameter) with a sterile pipette. When the agar had solidified, it was seeded with $0.25 \mathrm{ml}$ of spore suspension containing approximately 1,000 spores $/ \mathrm{ml}$ and spread with a glass rod. Serial water dilutions of phleomycin ( 500 to $6,000 \mathrm{ppm}$ ) or nystatin 
(100 to 1,000 units $/ \mathrm{ml}$ ) were prepared. Filter paper discs of $12.7 \mathrm{~mm}$ diameter were placed flat on the agar plates. Two discs were placed equidistant from the sides and from each other on each petri dish and gently pressed to the agar. Onto each disc, a $0.1 \mathrm{ml}$ sample of the antibiotic solution was immediately delivered using a $0.05 \mathrm{ml}$ sterile transfer loop. Six replicates of each antibiotic dilution were used in each experiment along with control discs on which only sterile water was placed.

The plates were incubated at about $75^{\circ} \mathrm{F}$ for 96 hours. The diameter of the inhibition zone was measured, and, when the area of inhibition was irregular in shape, the larger and smaller diameters were averaged for each treatment. The area of the inhibition zones was calculated exclusive of the area covered by the paper discs.

Triphenyl tetrazolium chloride (Matheson, Coleman, and Be11) was also assayed to differentiate in vitro variant biotypes. A range of concentrations from 0.01 to $0.1 \%$ was tested. Water solutions of tripheny1 tetrazolium chloride (TTC) were steam sterilized separately and added to the basic medium after sterilization.

\section{Isolation of Selected Clones}

Several clones were isolated on basic medium amended with nystatin (200 units $/ \mathrm{ml})$, phleomycin $(0.5$ and $1.0 \mathrm{ppm})$, pimaracin $(200 \mathrm{ppm})$, and cycloheximide $(100 \mathrm{ppm})$. The amended media were seeded with spore suspensions of wild-type cultures of B. cinerea (pepper, tomato, chrysanthemum, and strawberry isolates). Isolation of individual colonies was facilitated using either $1 \% \mathrm{~L}$-sorbose or $0.03 \%$ sodium desoxycholate added to the antibiotic media. Single-spore colonies growing on the 
highest concentration of the antibiotic media were transferred and maintained for approximately 12 months on an antibiotic medium of the same formulation from which the clone was selected, except that no paramorphogenic agent was included.

Several clones, originally from wild-type cultures of $\underline{B}$ - cinerea (pepper and tomato isolates), were also isolated on $0.05 \%$ TTC medium amended with $0.03 \%$ sodium desoxycholate. Red-colored and colorless colonies growing on the TTC medium were transferred to the basic medium.

\section{$\underline{\text { Pathogenicity Tests }}$}

Thirty-day-old pepper (Capsicum annuum L.) seedlings of the varieties California Wonder and Yolo Wonder were inoculated with the biotypes selected in media with various amendments. At least 100 seedlings in 4-inch clay pots were inoculated with each biotype.

Spore suspensions were adjusted to $10,000 \mathrm{spores} / \mathrm{ml}$ but, with some clones that sporulated poorly, a minimum of 5,000 spores $/ \mathrm{ml}$ was used. A drop of Tween 20 was added to the suspensions to facilitate dispersion of spores in the inoculum and wetting of leaf surfaces. The inoculum was applied to the plants with a De Vilbiss atomizer after which the plants were immediately covered with a polyethylene bag to maintain high moisture, and the pot set in an 8 -inch clay saucer placed on the greenhouse bench. The temperature during these experiments averaged about $58^{\circ} \mathrm{F}$ during the night and ranged from 70 to $95^{\circ} \mathrm{F}$ during the day. Data were recorded using the percentage of seedlings killed by each clone as an infection index. 


\section{Carbon Sources}

The basal medium described by Lilly and Barnett (55) was utilized in carbon source experiments. Lots of six liters of medium were prepared to insure that the basal medium for each experiment was the same. Ten grams/liter of each carbon source were used in all the experiments and the $\mathrm{pH}$ of the medium adjusted to 6.0 before sterilization. The basal medium and the carbon compounds were sterilized separately and mixed aseptically. Four $125 \mathrm{ml}$ flasks were used as culture vessels for each treatment, each flask containing $25 \mathrm{ml}$ of medium. One piece of the mycelium and agar cut with a cork borer about $3 \mathrm{~mm}$ in diameter was used to seed each flask of basal medium. The flasks were incubated at about $75^{\circ} \mathrm{F}$ and the mycelium was harvested four and nine days after inoculation, dried overnight at $100^{\circ}$, or $75^{\circ} \mathrm{C}$ for 24 hours, and weighed on an analytical balance.

In a preliminary experiment, 12 carbon sources were compared for supporting mycelial growth of three B. cinerea cultures isolated from pepper: type culture, a clone isolated on nystatin media (200 units/ml), and a clone isolated on basic medium amended with $0.03 \%$ sodium desoxycholate. Based on the results obtained in the preliminary experiment, this study was expanded to include four carbon sources (mannose, glucose, fructose, and glycerol) and 12 fungus clones (four clones isolated on TTC medium, two red-colored and two colorless single spore colonies; four clones selected on 200 units/ml nystatin; and four clones selected on $0.5 \mathrm{ppm}$ phleomycin medium. The type culture from pepper was used as a control in each experiment and flasks containing basal medium without carbon were seeded with each of the 12 clones. The mycelium was harvested after nine days' incubation. 


\section{Mycelial Inhibition}

The paper disc technique previously described was utilized in this study with the following modifications: the basic medium was prepared with distilled water and the $\mathrm{pH}$ adjusted to 6.5. Ten grams/liter of each of three carbon sources (mannose, fructose, and glycerol) were steam-sterilized separately and added aseptically to the basic medium. One-tenth ml of either nystatin $(1,000$ units $/ \mathrm{ml})$ or phleomycin $(6,000 \mathrm{ppm})$ was placed on a paper disc located in the center of each petri culture.

Four isolates were used in the first experiment: two clones isolated on phleomycin medium ( $0.5 \mathrm{ppm})$, one clone isolated on TTC medium and the wild isolate from pepper. In the second experiment, three isolates were used: two clones isolated on nystatin medium (200 units/ml) and the wild isolate from pepper. Six replicates of each carbon source were used in each experiment and the plates were incubated at about $75^{\circ} \mathrm{F}$ for 96 hours. The areas of the inhibition zones were calculated exclusive of the areas covered by the paper discs. 
RESULTS

Influence of Paramorphogenic Agents

Sodium desoxycholate restricted the increase in diameter of all Botrytis isolates tested. L-sorbose induced paramorphogenic growth

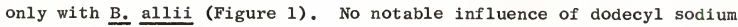

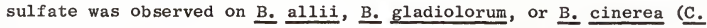
annum isolate), but restricted colonies were produced with an isolate of the latter species from $L$. esculentum and chrysanthemum. Hexachlorocyclohexane did not influence colony growth of any of the Botrytis species used (Table 1).

The period of influence of paramorphogenic agents was variable. The effect of L-sorbose on B. allii lasted more than 30 days, and only a slight increase in colony diameter was observed after this period. Detached spores from the conidiophores of paramorphic cultures produced additional restricted colonies after falling to the surface of the medium. The period of influence of sodium desoxycholate and dodecyl sodium sulfate lasted only a few days, after which colonies rapidly increased in diameter to cover the entire surface of the medium.

Both the number of colonies that developed and the size of individual colonies of all Botrytis species were reduced with the higher concentrations of sodium desoxycholate (above $500 \mathrm{ppm}$ ). In addition, the colonies remained restricted in size for a longer period of time. A similar but less pronounced effect was noted with dodecyl sodium sulfate. The higher concentrations of L-sorbose did not induce such an effect on B. $_{\text {allii. }}$. 


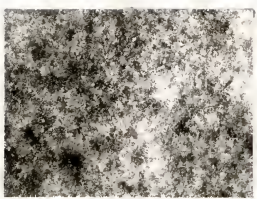

A
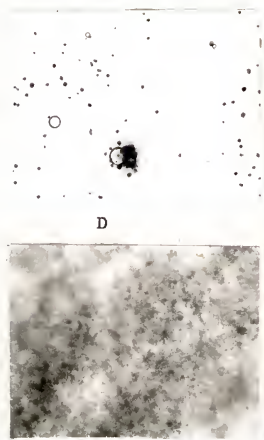

G

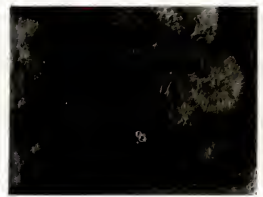

J

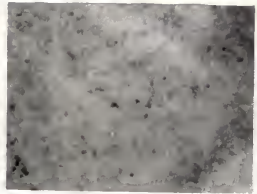

B

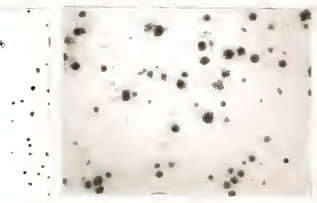

E

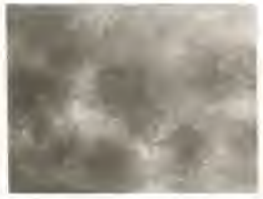

H

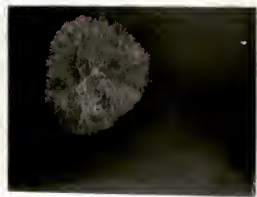

K

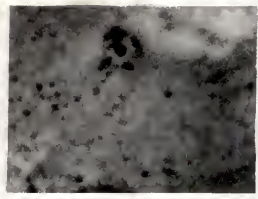

C

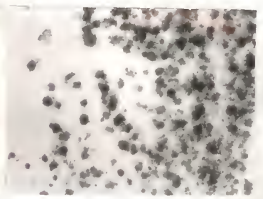

F

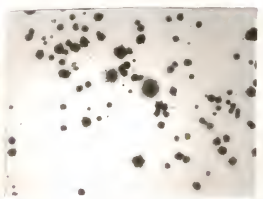

I

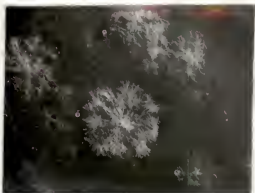

L

Figure 1.--Paramorphogenic effect of sodium desoxycholate, L-sorbose, and dodecyl sodium sulfate on $B$. cinerea (C. annuum isolate), left column, B. gladiolorum, middle column, and B. allii, right column, after 5-7 days. A, B, C) Control; $\overline{D,} \overline{E, F)} 0.03 \%$ sodium desoxycholate; G, H, I) $0.1 \%$ L-sorbose; J, K, L) $0.008 \%$ dodecyl sodium sulfate. Appr. $1.0 \mathrm{x}$. 


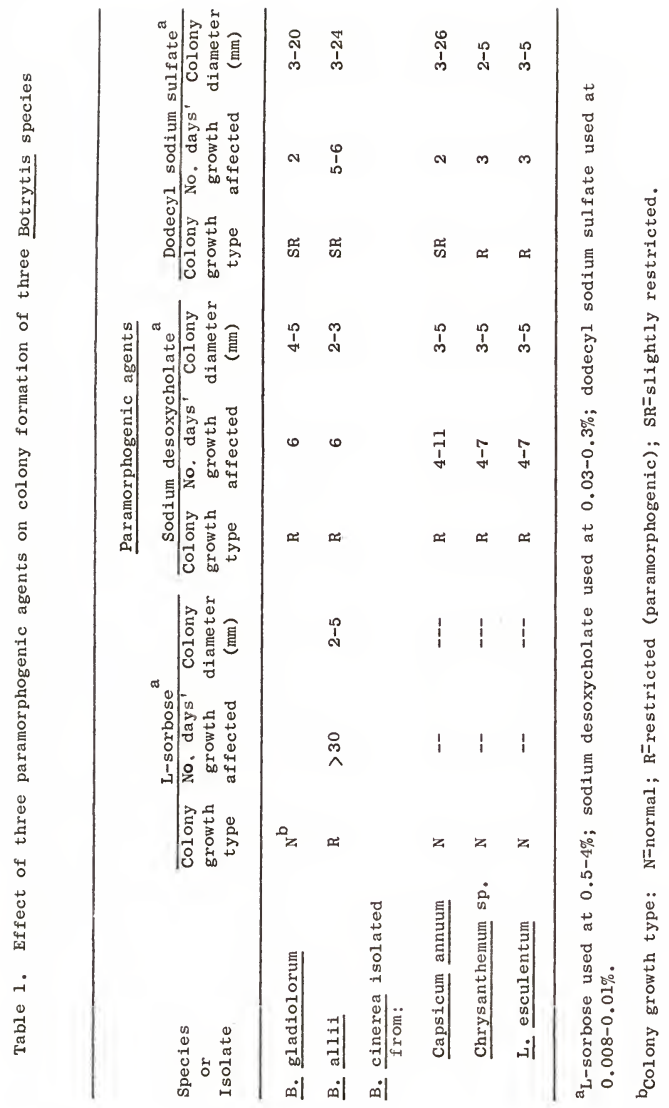


Colonies in each of the various replicates of sodium desoxycholate or L-sorbose treatment were uniform in diameter. This was also noted with the tomato and chrysanthemum isolates of $\mathrm{B}$. cinerea on dodecyl sodium sulfate medium. However, diameters of B. allii, B. gladiolorum, and $\underline{B}$. cinerea (pepper isolate) colonies were extremely variable on dodecyl sodium sulfate medium.

When high concentrations $(0.03-0.1 \%)$ of the latter paramorphogen were assayed, a marked toxic effect was observed and colony formation was inhibited above $0.07 \%$. At lower concentrations $(0.03,0.05 \%)$ nonsporulating colonies developed that were approximately $3 \mathrm{~mm}$ in diameter and immersed below the surface of the medium. When these colonies were transferred to the basic medium, no growth was observed. When colonies restricted by sodium desoxycholate and L-sorbose were transferred to the basic medium, growth was indistinguishable from that of the control colonies. B. cinerea and B. gladiolorum showed a tendency to form aerial mycelium on sodium desoxycholate and dodecyl sodium sulfate media.

From these experiments it was determined that the paramorphogenic agents sodium desoxycholate and L-sorbose do effectively restrict the growth of colonies of some Botrytis species.

\section{Inhibition of Botrytis Species}

by Antibiotics

B. allii was more susceptible to the antibiotics assayed than the other two species. B. gladiolorum and B. cinerea (wild isolate from pepper) tolerated higher concentrations of the antibiotics as shown in Table 2. Low concentrations of phleomycin completely inhibited mycelial growth of all three species. Inhibition by antibiotics was not influenced 
Table 2. Concentrations of five antiblotics required to inhibit mycelial growth of three Botrytis species (three experiments, each of four weeks incubation)

\begin{tabular}{|c|c|c|c|}
\hline Antibiotics & B. cinerea & B. allii & B. gladiolorum \\
\hline $\begin{array}{l}\text { Nystatin } \\
\text { (units/ml) }\end{array}$ & $100-150 / 200^{a}$ & $75-100 / 100$ & $100-125 / 150$ \\
\hline $\begin{array}{l}\text { Phleomycin } \\
\text { (ppm) }\end{array}$ & $10-15 / 20$ & $5-10 / 15$ & $10-20 / 25$ \\
\hline $\begin{array}{l}\text { P1maracin } \\
\text { (ppm) }\end{array}$ & $100-150 / 200$ & $100-125 / 150$ & $100-150 / 200$ \\
\hline $\begin{array}{l}\text { Cycloheximide } \\
\text { (ppm) }\end{array}$ & $150-250 / 300$ & $50-100 / 150$ & $150-250 / 300$ \\
\hline $\begin{array}{l}\text { Griseofulvin } \\
\text { (ppm) }\end{array}$ & $100-150 / 200$ & $50-100 / 100$ & $100-150 / 200$ \\
\hline
\end{tabular}

${ }^{a}$ Notable reduction of mycelial growth/minimum concentration that induced complete inhibition of colony formation and mycelial growth. 
by the addition of either $0.03 \%$ sodium desoxycholate or $1 \%$ L-sorbose to the medium.

Even though complete inhibition of mycelial growth was induced with the antibiotic concentrations noted, spore germination was only partially inhibited. Many germinating spores with but a few small mycelial filaments were observed on phleomycin, nystatin, and pimaracin media. When such spores were transferred to basic medium without antibiotic, some of them produced colonies while others did not. The same results were obtained when plates with (antibiotic) amended media were overlayed with basic medium (without antibiotic). When surviving colonies of B. allii and $\underline{B}$. cinerea on cycloheximide media (50 and $100 \mathrm{ppm}$ ) were overlayed with $0.05 \%$ TTC medium, only $B_{\text {. }}$ allii colonies appeared reddish after 48 hours' incubation.

Noticeable morphological changes were produced by phleomycin (10 ppm), cycloheximide (100 ppm), and griseofulvin (10 ppm). Reduction of branching, distortion of conidiophores, and reduction of sporulation were common effects. The detrimental effect of griseofulvin on $\underline{B_{0}}$ allii was very pronounced with the degree of severity apparently being directly correlated with increase in antibiotic concentration. At $10 \mathrm{ppm}$, the conidiophores were small, distorted, and sometimes curled, while at 20-50 ppm, most of the conidiophores were unbranched and necrotic. The medium immediately around the colonies became dark brown and frequently involved a sizable area. The same dark pigmentation of the medium was observed around restricted colonies on phleomycin medium.

The inhibition of Botrytis species by nystatin and phleomycin using the paper disc technique is presented in Figures 2 and 3 . When the calculated 
NYSTATIN.

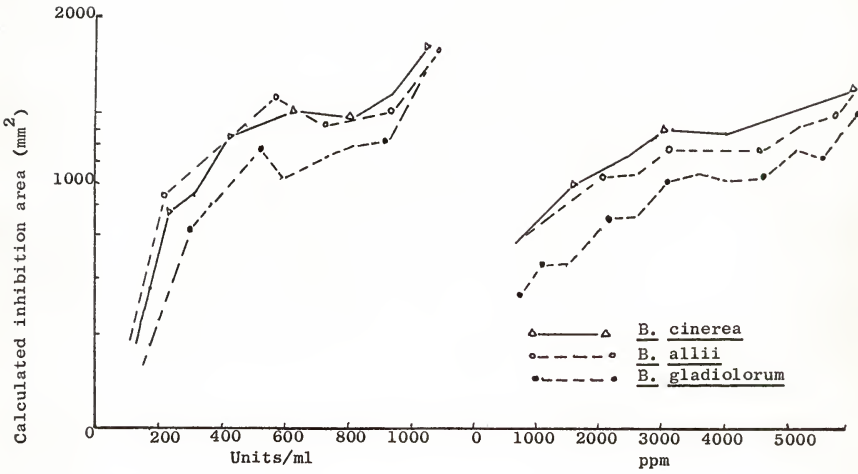

Figure 2. Average inhibition of three Botrytis species by nystatin and phleomycin - modified paper disc technique (Areas covered by paper discs subtracted from inhibition zones). 


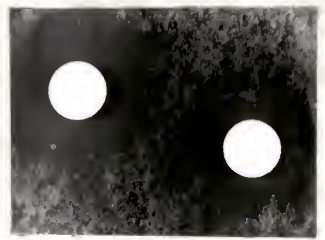

1

2

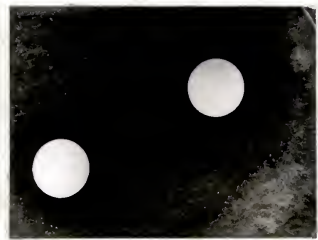

1.

2.
A

3

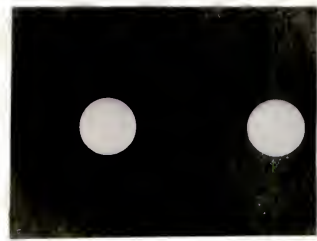

3.
4

4.

Figure 3.--Antibiotic inhibition of B. cinerea (type isolate from pepper) mycelial growth, using paper disc technique; (A, 1-4) phleomycin, $2000,3500,5000 \mathrm{ppm}$ and control, respectively; (B, 1-4) nystatin, 200, 500, 800 units/m1 and control, respectively. After 4 days' incubation. Appr. $1.0 \mathrm{x}$. 
inhibition areas were plotted, the shapes of the curves for the three species were consistently similar with each antibiotic. The more direct correlation between antibiotic concentration and area of inhibition was obtained with phleomycin. The greatest increase in effect of nystatin on inhibition occurred from 100 to 500 units $/ \mathrm{ml}$.

Germinating spores with a few small mycelial filaments were observed inside the inhibition areas. Some of these spores, when transferred to basic medium (without antibiotic), grew normally, while others did not grow further.

In these experiments, it was demonstrated that some antibiotics, in relatively low concentrations, do exert an inhibitory effect on spore germination and colony formation of some Botrytis species. Using the paper disc technique, it was possible to make quantitative determinations of the antibiotic inhibition of mycelial growth of Botrytis species.

\section{Pathogenicity Tests}

Type cultures of Botrytis species and biotypes selected on media with various amendments were tested for pathogenicity on pepper seedlings (var. California Wonder and Yolo Wonder). All the type isolates of the B. cinerea group were pathogenic (Table 3) as were all the clones selected on amended media (Tables 4 and 5 ).

Marked variation in the incidence of Botrytis infection were noted. Among the clones selected on nystatin medium (Table 4), some of the tolerant clones were more pathogenic than the type culture originally isolated from pepper. Clones 3 and 16 produced higher disease indices than the type culture, whereas clones 5 and 26 were less pathogenic. 
Table 3. Pathogenicity of eight Botrytis isolates on pepper seedlings (var. California Wonder) January-March, 1964

\begin{tabular}{llc}
\hline$\frac{1}{\text { Botrytis }}$ species & $\begin{array}{c}\text { Isolated } \\
\text { from }\end{array}$ & $\begin{array}{c}\text { Number of a } \\
\text { clants killed }\end{array}$ \\
\hline & Kenaf & 20 \\
& African violet & 7 \\
& Pomato & 13 \\
& Strawber & 18 \\
gladiolorum & Chrysanthemum & 10 \\
\hline allii & Gladiolus & 6 \\
\hline
\end{tabular}

${ }^{a}$ One hundred seedlings inoculated with each isolate. 
Table 4. Pathogenicity of eight clones of B. cinerea (pepper isolate) selected on nystatin medium (200 units/ml)

\begin{tabular}{ccr}
\hline Biotype & \multicolumn{2}{c}{ Percentage of plants killed } \\
\cline { 2 - 3 } & 1964 & 1965 \\
\hline No. 3 & 71 & 77.8 \\
10 & 9 & 20.8 \\
11 & 41 & -5 \\
14 & 0 & 99.0 \\
16 & 12 & 57.2 \\
20 & 75 & $-\ldots-$ \\
26 & 63 & 43.6 \\
Wild culture & 14 & --- \\
\hline
\end{tabular}

${ }^{a}$ At least 100 pepper seedlings were inoculated with each clone.

${ }^{b}$ Clones 10, 16, 26 unable to survive on nystatin medium. 
Table 5. Pathogenicity of 22 clones of B. cinerea isolated on phleomycin, cycloheximide, triphenyl tetrazolium chloride and sodium dodecyl sulfate media, January-March, 1965

$\mathrm{P}-48^{\mathrm{a}}$

$\mathrm{p}-49^{\mathrm{a}}$

$\mathrm{P}-50^{\mathrm{a}}$

$\mathrm{P}-56^{\mathrm{a}}$

$\mathrm{P}-77^{\mathrm{a}}$

$\mathrm{P}-80^{\mathrm{a}}$

$\mathrm{P}-81^{\mathrm{a}, \mathrm{c}}$

$\mathrm{P}-82^{\mathrm{a}}, \mathrm{c}$

P- $83^{\mathrm{a}, \mathrm{c}}$

$\mathrm{P}-85^{\mathrm{a}, \mathrm{c}}$

P-86 a, d

To- 2 , c

To- 3 b, c

To- 4 b, c

To -5 b,

To- $6^{b}, d$

To- $7^{b}, d$

p $-75^{a}$

$\mathrm{p}-62^{\mathrm{a}}$

$\mathrm{P}-67^{\mathrm{a}}$

Clone

designation

Isolation

medium
Percentage of

plants killed ${ }^{\mathrm{e}}$

Wild culture (pepper)

(tomato)

Phleomycin (0.5 ppm) 38

" 45

" $\quad 73$

" 28

" $\quad 27$

" (1.0 ppm) 77

Triphenyl tetrazolium chloride (500 ppm) 2

" "

" " " 118

" $\quad$ " 1184

" " " $1 " 23$

" " " 110

" " " 11

" " " 11

" $1 " \quad$ "

" $"$ " 57

" " $" 70$

Dodecyl sodium sulfate $(500 \mathrm{ppm}) \quad 79$

Cycloheximide (100 ppm) 0

" 0

22

${ }^{a}$ Selected from pepper isolate.

${ }^{b}$ Selected from tomato isolate.

${ }^{c}$ Colonies showing red color.

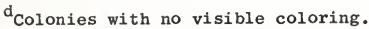

${ }^{\text {eAt }}$ least 100 pepper seedlings inoculated with each clone. 
Severe infection was produced by clones 50 and 80 selected on phleomycin media ( 0.5 and $1.0 \mathrm{ppm}$, respectively), but there was no correlation between colony appearance on TTC medium (colored vs. colorless clones) and pathogenicity. All the clones selected using this latter medium were pathogenic on pepper. Likewise, clone 75, isolated on basic medium amended with dodecyl sodium sulfate (500 ppm), was also pathogenic on pepper. Only a few lesions were observed on pepper seedlings inoculated with clones 62 and 67 isolated on cycloheximide media. However, the environmental conditions during pathogenicity tests with these clones were unfavorable for infection.

From these experiments, it was concluded that the amendments used were not satisfactory to distinguish pathogenic from non-pathogenic biotypes.

Effect of Carbon Sources on Growth

of Selected Clones

Preliminary experiments conducted during this investigation suggested the possibility that the carbon source in the basic medium influenced inhibition of Botrytis by antibiotics. This question became important since glycerol was the only carbon source for the basic medium utilized in other phases of this investigation.

To determine if different carbon sources noticeably influenced growth of clones selected on amended media, two clones and a type culture of B. cinerea (pepper isolate), were grown on 12 different carbon source media.

In Table 6 are presented the results of these experiments. Mannose, glucose and sucrose proved to be the better carbon sources for all three 


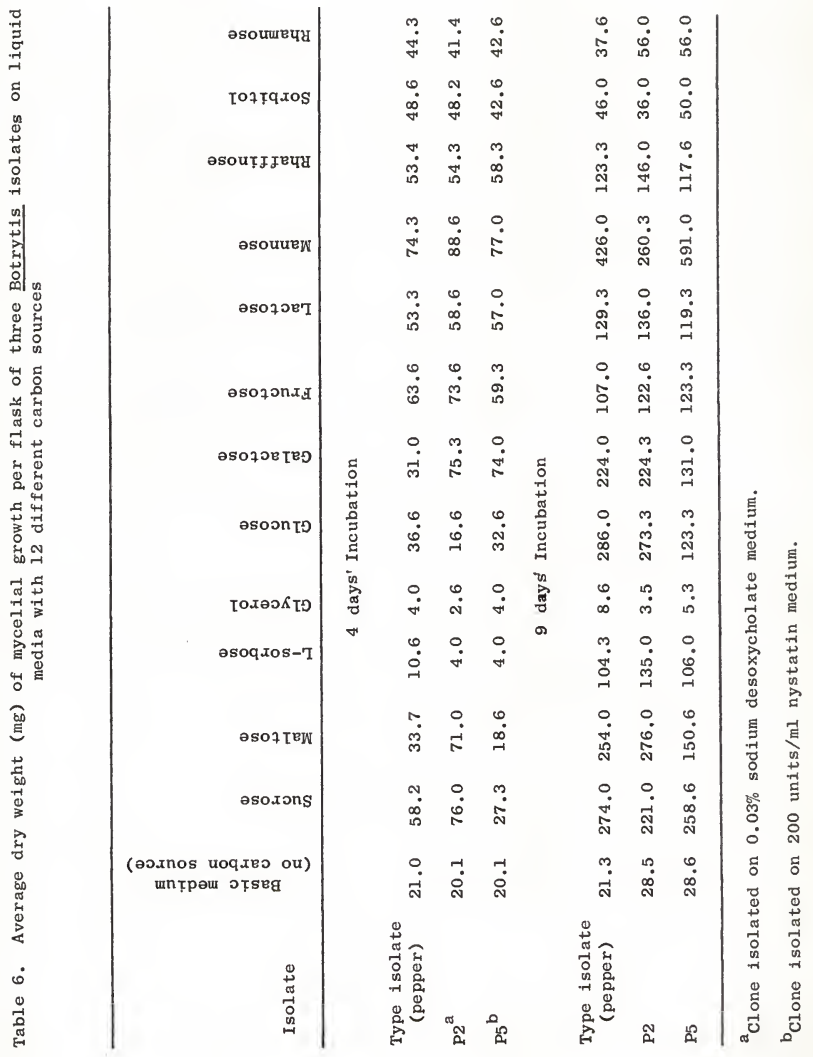


isolates. Less mycelial growth was produced on fructose, maltose, galactose, and L-sorbose media. Sorbitol, rhamnose, raffinose, and lactose supported poor growth, but mycelium production by the isolates on glycerol medium was extremely scanty. Sparse mycelial growth was observed after four days' incubation, but, after nine days, the yield of mycelium was significantly greater.

Mycelial growth produced by 12 selected clones grown on four carbon sources is shown in Table 7. Maximum growth was obtained in the glucose medium, but poor yields were obtained from all clones with glycerol. Most of the clones grew better in mannose than in fructose media, although clones P22 and To7 produced more mycelial growth on the fructose medium. Mannose gave better growth than fructose.with clones P78 and the pepper type isolate. There was no notable difference in utilization of carbon sources among clones selected on media with different amendments. Likewise, mycelial yield of clones isolated from red and colorless colonies on TTC medium was not noticeably different on the various carbon sources. It is evident from this study that most of the carbon sources supported better growth than glycerol. In addition, clones isolated from media with different amendments did not greatly differ in mycelial production on the various sugars.

Influence of Carbon Source on Antibiotic Inhibition of Mycelial Growth

Following the determination that mycelial growth of clones was decidedly affected by carbon source, experiments were conducted to determine the influence of three carbon sources on the inhibition of mycelial growth by antibiotics. Two experiments were completed using the 
Table 7. Weight (mg) of dried mycelium per flask produced by 13 clones of B. cinerea (pepper isolate) grown in liquid media with four carbon sources after nine days' incubation

\begin{tabular}{llll}
\hline Clones Mannose $\quad$ Fructose Glycerol Glucose & $\begin{array}{c}\text { Basal Medium } \\
\text { no carbon }\end{array}$
\end{tabular}

Clones selected on 0.5 ppm phleomycin medium

$\begin{array}{llllll}\text { P-48 } & 228.5 & 185.8 & 73.85 & 253.9 & 42.0 \\ \text { P-49 } & 311.8 & 251.8 & 67.25 & 325.8 & 56.8 \\ \text { P-50 } & 243.2 & 229.0 & 94.42 & 303.1 & 42.0 \\ \text { P-78 } & 305.1 & 163.3 & 60.85 & 211.3 & 40.5\end{array}$

Clones selected on 200 units/ml nystatin medium

$\begin{array}{llrrrr}\text { p-3 } & 238.1 & 272.3 & 63.00 & 280.3 & 40.5 \\ \text { P-5 } & 360.5 & 308.8 & 121.25 & 486.3 & 25.5 \\ \text { p-11 } & 298.1 & 267.5 & 99.47 & 325.4 & 50.3 \\ \text { P-22 } & 345.8 & 308.4 & 142.95 & 297.9 & 98.8\end{array}$

Clones selected on $0.5 \%$ TTC medium

\begin{tabular}{|c|c|c|c|c|c|}
\hline$P-85^{b}$ & 184.9 & 158.4 & 78.50 & 186.0 & 55.0 \\
\hline To- $2^{b}$ & 308.6 & 279.8 & 87.50 & 346.0 & 10.0 \\
\hline P- $86^{c}$ & 236.5 & 168.1 & 86.85 & 254.6 & 41.0 \\
\hline To- $7^{\text {c }}$ & 208.6 & 232.5 & 65.88 & 230.8 & 20.7 \\
\hline
\end{tabular}

Type isolate

$\begin{array}{llllll}\text { (pepper) } & 313.6 & 241.4 & 87.3 & 286.4 & 84.3\end{array}$

average of four replicates in each of two experiments.

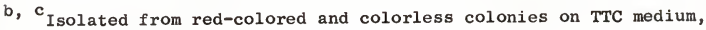
respectively. 
paper disc technique. Table 8 presents the effects of mannose, fructose, and glycerol on the area with no mycelial growth by clones isoiated on phleomycin and TTC media and the type isolate from pepper. According to the statistical analyses, the only significant differences in inhibition areas were those obtained on glycerol medium as opposed to either fructose or mannose media using clones To7 and P49. No effect of carbon source on antibiotic activity was noted with clone P50 or the type isolate.

A summarization of the influence of the same three carbon sources on the inhibition areas of two clones isolated on nystatin medium ( 200 units/ml) and the type isolate from pepper is presented in Table 9. Again, the only significant differences were between the inhibition areas on the glycerol medium and those on either fructose or mannose media when clone Pll was used. With the other two cultures, the differences in areas with no mycelial growth were not significant.

The sugars used as caitun sources in these experiments were found to directly affect mycelial inhibition by antibiotics. Of the sugars used, the greatest areas of inhibition were consistently obtained on the glycerol medium, while the smallest areas were produced on the fructose medium. These results, and those of the previous section, illustrate a consistent negative correlation between utilization of sugars and area of mycelial inhibition. 
Table 8. Influence of three carbon sources on phleomycin $(6,000 \mathrm{ppm})$ inhibition of mycelial growth of $B_{\text {. cinerea after }}$ 96 hours' incubation

\begin{tabular}{lcccc}
\hline & & Inhibition area $\left(\mathrm{mm}^{2}\right)^{\mathrm{a}}$ & \\
$\begin{array}{l}\text { Carbon } \\
\text { source }\end{array}$ & $\begin{array}{l}\text { Clone } \\
\text { To } 7^{\mathrm{b}}\end{array}$ & $\begin{array}{l}\text { Clone } \\
\text { P49 }^{\mathrm{c}}\end{array}$ & $\begin{array}{l}\text { Clone } \\
\text { P50 }^{\mathrm{c}}\end{array}$ & $\begin{array}{c}\text { Type } \\
\text { culture }\end{array}$ \\
\hline Mannose & $620.4^{1} * *^{\mathrm{d}}$ & $979.5^{1} *$ & $711.9^{1}$ & $729.7^{1}$ \\
Fructose & $573.7^{1} * *$ & $874.5^{1} *$ & $550.1^{1}$ & $670.6^{1}$ \\
Glycerol & $999.2^{2}$ & $1,155.6^{2}$ & $734.4^{1}$ & $827.2^{1}$ \\
\hline
\end{tabular}

anhibition area exclusive of that covered by the paper disc.

${ }^{b}$ Clone isolated from a non-colored colony selected on TTC medium.

$\mathrm{c}_{\mathrm{Cl}}$ one $\mathrm{s}$ isolated from single colonies selected on $0.5 \mathrm{ppm}$ phleomycin medium.

$\mathrm{d}_{\text {Figures in the same column not having the same superscript number }}$ are significantly different at the $5 \%(*)$ or $1 \%$ level (**) (29). 
Table 9. Influence of three carbon sources on nystatin $(1,000$ units $/ \mathrm{ml})$ inhibition of mycelial growth of B. cinerea after 96 hours' incubation

\begin{tabular}{|c|c|c|c|}
\hline & & area $\left(\mathrm{mm}^{2}\right)$ & \\
\hline Carbon & $\begin{array}{c}\text { Clone } \\
\text { P5 }\end{array}$ & $\begin{array}{l}\text { C1one } \\
\text { P11 }\end{array}$ & $\begin{array}{l}\text { Type } \\
\text { culture }\end{array}$ \\
\hline Mannose & $203.0^{1}$ & $169.5^{1} * *^{c}$ & $492.5^{1}$ \\
\hline Fructose & $120.1^{1}$ & $130.7^{1} * *$ & $376.2^{1}$ \\
\hline Glycerol & $263.9^{1}$ & $579.3^{2}$ & $658.9^{1}$ \\
\hline
\end{tabular}

anhibition area exclusive of that covered by the paper disc.

${ }^{b} \mathrm{Clones}$ isolated from single colonies selected on 200 units $/ \mathrm{ml}$ nystatin medium.

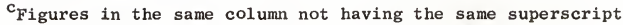
number are significantly different at the $5 \%$ (*) level or $1 \%$ level (**) (29). 


\section{DISCUSSION}

The nature of the paramorphogenic effect has been studied by several investigators. Tatum (83) indicated that the activity of sodium desoxycholate and other materials was related to surface activity and limited to certain anionic compounds. Dodecyl sodium sulfate, used in this research, is also an anionic surface-active agent. The effect of Lsorbose was not due to surface activity. De Terra and Tatum $(25,26)$ found that the colonial growth of Neurospora was due to alteration of the cell wall composition. Microscopically, the hyphae of sorbose-grown colonies were characterized by a great increase in the number of branches and cross walls per unit length of hypha and by the induction of branching at hyphal tips. This phenomenon was rarely seen in young cultures.

De Serres et al. (24) found that sorbose exerts a "toxic" effect on wild-type conidia or ascospores plated in sorbose-sucrose media which have been filter-sterilized or autoclaved for short periods. Brockman and De Serres (12) determined that "sorbose toxicity" was eliminated or minimized in Neurospora conidia or ascospores by replacing sucrose with a mixture of fructose and glucose as the carbon source. Tatum et al. (83) indicated that the paramorphogenic effect of L-sorbose could be reversed, apparently competitively, by other sugars, i.e., glucose, sucrose, and more slowly by maltose and mannose. A similar effect of sucrose on L-sorbose medium was observed in the study reported here, but the effect of sodium desoxycholate was not reversed when sucrose was substituted for glycerol in the basic 
medium. Different chemical composition of the paramorphogens may account, in part at least, for the different responses to sucrose.

Tatum et al. (83) indicated that the use of glycerol as a carbon source in the synthetic medium facilitated the induction of restricted growth. A similar influence of glycerol was observed on Botrytis as well as other phytopathogens (2). In addition, sporulation of Botrytis and Neurospora (4) was stimulated by glycerol.

Of the materials used in this study, sodium desoxycholate and L-sorbose were the most satisfactory for restricting increase in diameter of Botrytis colonies. At the lower concentrations assayed (0.5-1.0\% L-sorbose and $0.03 \%$ sodium desoxycholate), no deleterious effect was observed and the influence of the paramorphogens was only temporary. Hexachlorocyclohexane was not a satisfactory paramorphogenic agent because of its insoluble nature.

Differences in antibiotic tolerance among three Botrytis species were evident in this investigation. $\underline{B}$. allii was more susceptible to all the antibiotics assayed than $\underline{B}$. cinerea and $\underline{B}$. gladiolorum. Inhibition of $\underline{B}$. allii by antibiotics, as well as the effect of L-sorbose, could be a valuable criterion to assist in the taxonomy of Botrytis species.

A direct correlation was found between antibiotic dose and mycelium inhibition area of Botrytis species with both nystatin and phleomycin. Increase in concentration of the latter was more consistently reflected in greater inhibition area than with the former, particularly within the 500900 units/ml concentration range of nystatin. This could be attributed, in part, to differences in diffusion and biological stability of the antibiotics in the agar media. Nystatin is insoluble in water, very unstable 
in aqueous solution, and rapidly inactivated by acid, alkali, heat, light, and oxygen (79). There is incomplete information about the chemical structure and the physical properties of phleomycin, except that Smale et al. (5) indicated that it is basic and soluble in water.

No reports of previous studies concerning the effect of phleomycin and pimaracin on Botrytis could be found in the literature. The biological activity of griseofulvin was studied by Brian (9) who found that $10 \mu \mathrm{g} / \mathrm{ml}$ caused excessive branching and distortion of the hyphae of B. allii, and still lower concentrations $(0.1 \mu \mathrm{g} / \mathrm{ml})$ caused a marked spiral wave of the hyphae. Relatively high concentrations $(50-100 \mu \mathrm{g} / \mathrm{ml})$ did not prevent germination of B. allii conidia. B. cinerea, B. tulipae, and B. narcissicola also showed growth reduction and distortion of the hyphae. Aytoun (3) indicated that griseofulvin is not translocated within the mycelium and acts only on a small region of the hypha around the tip.

There is considerable evidence that nystatin, as well as other polyene anti-fungal antibiotics, damages the yeast cell-membrane and decreases its ability to take up and retain critical metabolites (20). The effect of cycloheximide on germination of $\mathrm{B}$. cinerea spores was investigated by Thanos (84) and on mycelial growth by Wallen et al. (85). Wallen and associates found that the growth of $B$. cinerea was slightly affected by 15 ppm, but, at $50 \mathrm{ppm}$, growth was strongly retarded, although not completely inhibited. Inhibition of mycelial growth by cycloheximide was determined at higher concentrations $(200 \mathrm{ppm})$ in the present research). It is possible that the primary action of cycloheximide on yeast is the inhibition of protein synthesis (73). 
Elimination of wild-type cells from a mixed population of mutants and wild-type yeast has been accomplished using antibiotics (59). In these studies, the lower limits of tolerance of phleomycin and cycloheximide were determined when the amended media were seeded with low spore concentrations (200 spores/ml). In this manner, it was possible to select individual colonies presumably tolerant to the antibiotics. When the medium was seeded heavily, it was difficult to differentiate individual colonies, although it was noted that the number of colonies surviving in amended media was drastically reduced by the selective effect of the antibiotic. However, it was not possible to obtain an accurate estimate of the selective reduction in spore population with increasing concentrations of the antibiotics.

Several clones selected on $0.5 \mathrm{ppm}$ phleomycin medium (isolated from pepper, chrysanthemum, and strawberry) produced poor, non-sporulating mycelium when maintained on phleomycin medium. When those colonies were transferred to a basic medium without antibiotic, there was some increase in mycelial growth but not in sporulation. On the assumption that these clones were nutritionally deficient, transfers were made to a synthetic medium supplemented with either peptone, casein hydrolysate, yeast extract, blood hydrolysate, or a vitamin mixture. However, no further improvement in growth or sporulation was observed on any of the media. The possibility remains that the clones selected were auxotrophic mutants with more exacting requirements than could be determined in this preliminary study.

It was sometimes difficult merely to maintain clones isolated on nystatin (200 units/ml), cycloheximide (100 ppm), and pimaracin (200 ppm) media and several did not survive on the antibiotic medium from which they 
were originally selected. Other clones tolerant to cycloheximide and pimaracin grow slowly and sporulated poorly at first, but, after a sixmonth period of culture on the respective antibiotic media, mycelial growth and sporulation improved somewhat. A similar but less pronounced effect was observed with clones selected on phleomycin medium (from the pepper type isolate) which grew better on phleomycin medium than clones isolated and maintained on nystatin, pimaracin, and cycloheximide media. Some improvement in mycelial growth and sporulation was obtained with all clones when sucrose was substituted for glycerol in the amended media.

The paper disc technique used in this research could be adapted to assess quantitatively variation produced in vivo. External environmental conditions must be critically controlled to use the paper disc technique most effectively.

Differences in cultural stability, primarily sporulation, of type cultures of Botrytis species were found when they were maintained for two years in vitro. B. gladiolorum sporulated poorly even when sucrose was substituted for glycerol as a carbon source in the basic medium. Some increase in sporulation was obtained when the medium was supplemented with thiamine $(100 \mu \mathrm{g} / 1)$, biotin $(5 \mu \mathrm{g} / 1)$, folic acid $(4 \mu \mathrm{g} / 1)$ and piridoxine hydrochloride $(500 \mu \mathrm{g} / \mathrm{I})$. Wilcox (92) found that $\underline{\mathrm{B}}$. gladiolorum was deficient mainly in thiamine. B. allii also deteriorated as a result of continual in vitro culture, but mycelial growth and sporulation improved when the supplements mentioned above were added to the medium.

Within the $B$. cinerea group, the type culture from pepper was found to be more stable than the other isolates. Growth and sporulation were not ticed by continuous culture for two years. The other type isolates of 
the cinerea group (isolated from tomato, chrysanthemum, strawberry, kenaf, and African violet) were more unstable in cultural characteristics during the course of this study. In general, however, continuous culture of these isolates on synthetic media resulted in a gradual decrease in sporulation.

Colony appearance on TTC has been correlated with pathogenicity for some bacterial plant pathogens $(49,74)$. Cultures derived from redcolored colonies were either weakly pathogenic or non-pathogenic, whereas cultures from white colonies with pink centers were highly pathogenic. Colony appearance of B. cinerea (pepper isolate) on TTC medium could not be correlated with pathogenicity, both red-colored and white colonies being pathogenic on pepper. Smale (74) also found that individual colonies of Xanthomonas phaseoli with color differences did not differ in degree of pathogenicity.

Lederberg (52) used TTC as an indicator to distinguish between E. coli strains capable of fermenting various sugars. Raut (68) used the Lederberg technique to isolate mutant clones of Saccharomyces cerevisiae to ferment glucose following ultraviolet irradiation. Clones derived from the white colonies, which were thought to be non-fermenters, were capable of fermenting glucose as were those from the red colonies. Raut (68) concluded that white colonies differed from normal colonies in being unable to absorb oxygen. Furthermore, he indicated that white colonies were deficient in some of the camponents of the cytochrome system and that this deficiency was inherited.

It was not possible to differentiate in vitro pathogenic from nonpathogenic biotypes with the antibiotics used in these studies. This 
may have resulted, in part at least, from the relative stability (homogeneity) of the pepper type culture from which most of the clones were isolated. Furthermore, it is generally conceded that antibiotics exert less effect on fungi than on some other types of microorganisms. The environmental conditions during the winter of 1964-1965 were unfavorable for Botrytis infection most of the season, although inoculations were made during short periods of cool weather.

Lilly and Barnett (55) studied the utilization of sugars by 57 species

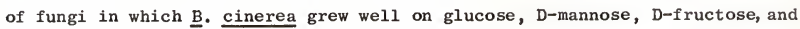
maltose. Reduced growth was obtained with D-galactose, L-arabinose, D-xylose, and L-sorbose. Similar utilization of sugars occurred in this investigation; moreover, glycerol was not one of the better carbon sources for the Botrytis species used. The poor utilization of glycerol by these Botrytis isolates helps to elucidate, in part, the role of this carbon source in inducing paramorphogenic growth of colonies.

Mycelial inhibition by antibiotics was found to be inversely related to sugar utilization. Bradley (8), using a different technique, found no correlation between respiratory quotient and susceptibility to cycloheximide for 17 fungi grown in a glucose medium. More basic knowledge is needed about the influence of essential metabolites in the inhibition and tolerance of plant pathogens to antibiotics. This information could be important from the applied aspect of plant pathology to utilize antibiotics more effectively for plant disease control.

Adaptive changes in virulence of plant pathogens continues to be of major concern to plant pathologists $(14,69,87)$. The imperfect fungi, in which there is no recombination of heritable traits through a sexual 
stage, are appropriate tools with which to study the basic mechanisms of pathogenicity. The techniques devised in these investigations and the results obtained serve to demonstrate the need for further studies to devise reliably satisfactory means to assess asexual variability in phytopathogenic fungi. 


\section{SUMMARY}

This research was conducted to develop techniques which could be applied to assess the inherent asexual variability of some Botrytis species and be extended to study other culturally unstable fungal phytopathogens.

Sodium desoxycholate $(0.03-0.3 \%)$ and L. sorbose $(0.5-4 \%)$ were the paramorphogenic agents better adapted to restrict increase in diameter of Botrytis colonies. Sodium dodecyl sulfate $(0.006-0.01 \%)$ had less influence and hexachlorocyclohexane $(0.03-0.1 \%)$ did not restrict colony growth.

B. allii was more susceptible to all antibiotics used than were B $_{0}$ cinerea and B. gladiolorum. Even though complete inhibition of mycelial growth was induced with five antibiotics (nystatin, phleomycin, pimaracin, cyclohexamide, and griseofulvin), spore germination was only partially inhibited.

A method, referred to as the paper disc technique, was used to determine the relation between concentration of phleomycin and nystatin and inhibition of mycelial growth of three Botrytis species. A direct correlation was found between phleomycin concentration (500-600 ppm) and mycelial inhibition, but the only notable increase in effect of nystatin on mycelial inhibition occurred from 100 to 500 units/ml. The paper disc technique proved to be a satisfactory method for quantitative measurement of antibiotic inhibition. 
Clones were selected on media amended with L-sorbose or sodium desoxycholate and concentrations of the antibiotics mentioned above or tryphenyl tetrazolium chloride. They were maintained throughout the course of this study on the same medium prepared without paramorphogenic materials. Following pathogenicity tests on pepper seedlings, it was concluded that these materials were unsatisfactory to distinguish pathogenic vs. non-pathogenic clones in vitro since all of the clones tested induced disease symptoms. Some of the clones were unable to survive for a prolonged period of time on the antibiotic medium on which they were originally selected.

In experiments to determine the influence of carbon sources on tolerance to antibiotics, all of the clones tested utilized mannose, glucose, and fructose better than glycerol. There were no notable differences in utilization of sugars among clones selected on media amended with different antibiotics. Likewise, clones isolated from red and colorless colonies in triphenyl tetrazolium chloride medium did not differ in their ability to utilize the various carbon sources. An inverse correlation was found, however, between sugar utilization and mycelial inhibition with both nystatin $(1,000$ units $/ \mathrm{ml})$ and phleomycin $(6,000 \mathrm{ppm})$. In the studies summarized above, it was demonstrated that paramorphogenic agents can be useful in facilitating the selection of large numbers of single-spore colonies of some phytopathogenic fungi. While the antibiotics assayed did not serve to distinguish the desired biotypic differences, the procedures developed could be utilized with a wide range of selective amendments. However, particular attention should be given to the influence of ingredients in the basic and amended media to avoid misinterpretation of results. 


\section{LITERATURE CITED}

1. Adelberg, E. A., and J. W. Myers. 1953. Modification of the penicillium technique for the selection of auxotrophic bacteria. J. Bacteriol. 65: 348-353.

2. Ampuero, E., D, D. Netzer, and A. A. Cook. Influence of two paramorphogenic agents on some plant pathogenic fungi. Unpublished.

3. Aytoun, R. S. C. 1956. The effects of griseofulvin on certain phytopathogenic fungi. Ann. Bot. 20: 297-305.

4. Barrat, R. W. and L. Garnjobst. 1949. Genetics of a colonial microconidiating mutant strain of Neurospora crassa. Genetics $34: 351-67$.

5. Beadle, G. W. and E. L. Tatum. 1941. Genetic control of biochemical reactions in Neurospora. Nat. Acad. Sci., Proc. 27: 499-506.

6. Beadle, G. W. and E. L. Tatum. 1945. Neurospora. II. Methods of producing and detecting mutations concerned with nutritional requirements. Am. J. Bot. 32: 678-686.

7. Boone, D. M., D. M. Kline, and G. W. Keitt. 1957. Venturia inaequalis (Cke.) Wint. III. Pathogenicity of induced biochemical mutants. Am. J. Bot. 44: 791-796.

8. Bradley, S. G. 1962. Relationship between sugar utilization and the action of cycloheximide on diverse fungi. Nature 194: 315-316.

9. Brian, P. W. 1949. Studies on the biological activity of griseofulvin. Ann. Bot. 13: 59-77.

10. Brierley, W. B. 1929. Variation in fungi and bacteria. Int. Congr. Plant Sci. Ithaca, New York, Proc. 2: 1629-1654.

11. Brierley, W. B. 1931. Biological races in fungi and their significance in evolution. Ann. Appl. Biol. 18: 420-434.

12. Brockman, H. E. and F. J. De Serres. 1963. "Sorbose toxicity" in Neurospora. Am. J. Bot. 50: 709-714.

13. Buxton, E. W. 1956. Heterokaryosis and parasexual recombination in pathogenic strains of Fusarium oxysporum. J. Gen. Microbiol. 15: 133-139. 
14. Buxton, E. W. 1959. Mechanism of variation in Fusarium oxysporum in relation to host-parasite interactions, p. $\overline{183-191}$. In Plant pathology, problems and progress. 1908-1958. 1959. Univ. Wisconsin Press. Madison.

15. Buxton, E. W. 1960. Heterocaryosis, saltation and adaptation. Vol. 11, p. 359-405. In Horsfall, J. G., and A. E. Dimond (Ed.) Plant Pathology. Academic Press. New York.

16. Chiu, W. F., and J. C. Walker. 1949. Physiology and pathogenicity of the cucumber black-rot fungus. J. Agr. Res. 78: 589-615.

17. Christensen, C. M., E. C. Stakman, and J. J. Christensen. 1947. Variation in phytopathogenic fungi. Annu. Rev. Microbiol. 1: 61-84.

18. Christensen, J. J., and J. M. Daly. 1951. Adaptation in fungi. Annu. Rev. Microbiol. 5: 57-70.

19. Christensen, J. J., and J. E. De Vay. 1955. Adaptation of plant pathogens to host. Annu. Rev. Plant Physiol. 6: 367-392.

20. Cirillo, V. P., M. Harsch, and J. O. Lampen. 1964. Action of the polyene antibiotics filipin, nystatin and $\mathrm{N}$-acetylcandidin on the yeast cell membrane. J. Gen. Microbiol. 35: 240-259.

21. Davis, B. D. 1948. Isolation of biochemically deficient mutants of bacteria by penicillium. J. Am. Chem. Soc. 70:4267.

22. Day, R. P. 1960. Variation in phytopathogenic fungi. Annu. Rev. Microbiol. 14: 1-16.

23. Dekker, J. 1963. Antibiotics in the control of plant diseases. Annu. Rev. Microbiol. 17: 243-262.

24. De Serres, F. T., H. G. Kolmark, and H. E. Brockman. 1962. Factors influencing the survival of Neurospora crassa conidia in sorbosesucrose media. Nature 193: $556-557$.

25. De Terra, N., and E. L. Tatum. 1963. Colonial growth of Neurospora. Science 134: 1066-1068.

26. De Terra, N., and E. L. Tatum. 1963. A relationship between cell wall structure and colonial growth in Neurospora. Am. J. Bot. 50: 669-677.

27. Dickinson, S. 1932. The nature of saltation in Fusarium and Helminthosporium. Minnesota Agr. Exp. Sta. Bul. 88 .

28. Dulaney, E. L., A. H. Larsen, and E. O. Stapley. 1955. A note on the isolation of microorganisms from natural sources. Mycologia 47: 420-422. 
29. Duncan, D. B. 1955. Multiple range and multiple F tests. Biometrics 11: $1-42$.

30. Dutta, S. K., C. V. Hall, and E. G. Heyne. 1960. Pathogenicity of biochemical mutants of Colletotrichum lagenarium. Bot. Gaz. 121: 166-170.

31. Erwin, D. C., G. A. Zentmyer, J. Galindo, and J. S. Niederhauser. 1963. Variation in the genus Phytophthora. Annu. Rev. Phytopathol. 1 : 375-396.

32. Fincham, J. R. S., and P. R. Day. 1963. Fungal genetics. F. A. Davis Co. Philadelphia. 300 p.

33. Fisher, G. W., and C. S. Holton. 1957. Biology and control of the smut fungi. Ronald Press Co., New York. 622 p.

34. Friedman, B. A. 1964. Carbon sources and tetrazolium agar to distinguish virulence in colonies of Erwinia carotovora. Phytopathology 54: 494-495.

35. Fries, N. 1947. Experiments with different methods of isolating physiological mutations of filamentous fungi. Nature 159: 199.

36. Gabrielson, R. L., and R. G. Grogan. 1964. The celery late blight organism Septoria apiicola. Phytopathology 54::1251-1257.

37. Hansen, H. N., and R. E. Smith. 1932. The mechanism of variation in imperfect fungi; Botrytis cinerea. Phytopathology 22: 953-964.

38. Hansen, H. N. 1938. The dual phenomenon in imperfect fungi. Mycologia 30: 442-455.

39. Hansen, H. N. 1942. Heterokaryosis and variability. Phytopathology 32: $639-640$.

40. Hansen, H. N, and W. C. Snyder. 1943. The dual phenomenon and sex in Hypomyces solani f. cucurbitae. Am. J. Bot. 30: 419-422.

41. Huddleson, I. F., and B. Baltzer. 1950. Differentiation of bacterial species and variation within species by means of $2-3-5$ triphenyl tetrazolium chloride in culture medium. Science 112: $651-652$.

42. Jinks, J. L. 1952. Heterokaryosis: A system of adaptation in wild fungi. Roy. Soc. (London) Proc. Ser B. 140: 83-106.

43. Johnson, T. 1953. Variation in the rust of cereals. Biol. Rev. 28: 105-157.

44. Johnson, L. F. 1957. Effect of antibiotics on the numbers of bacteria and fungi isolated from soil by the dilution plate method. Phytopathology 47: 630-631. 
45. Katznelson, H., and M. D. Sutton. 1951. Inhibition of plant pathogenic bacteria in vitro by antibiotics and quaternaria ammonium compounds. Can. J. Bot. 29: 270-278.

46. Keitt, G. W., and M. H. Langford. 1941. Venturia inaequalis (Cke.) Wint, I. A ground work for genetic studies. Am. J. Bot. 28: 805820 .

47. Keitt, G. W., and M. H. Langford. 1941. A preliminary report on genetic studies on pathogenicity and the nature of saltation in Venturia inaequalis. Phytopathology 31: 1142 .

48. Keitt, G. W., and D. M. Boone. 1954. Induction and inheritance of mutant characters in Venturia inaequalis in relation to its pathogenicity. Phytopathology $44: 362-370$.

49. Kelman, A. 1954. The relationship of pathogenicity in Pseudomonas solanacearum to colony appearance on a tetrazolium medium. Phyto-

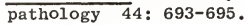

50. Kline, D. M., D. M. Boone, and C. W. Keitt. 1957. Venturia inaequalis (Cke.) Wint. XIV. Nutritional control of pathogenicity of certain induced biochemical mutants. Am. J. Bot. 44: 797-803.

51. Lederberg, J., and E. L. Tatum. 1946. Detection of biochemical mutants of microorganisms. J. Biol. Chem. 165: 381-382.

52. Lederberg, J. 1948. Detection of fermentative variants with tetrazolium. J. Bacteriol. 56: 695 .

53. Lederberg, J., and E. M. Lederberg. 1952. Replica plating and indirect selection of bacterial mutants. J. Bacteriol. 63: 399406.

54. Lein, J., H. K. Mitchell, and M. B. Houlahan. 1948. A method for selection of biochemical mutants of Neurospora. Nat. Acad. Sci. Proc. 34: 435-442.

55. Lilly, V. G., and H. L. Barnett. 1953. The utilization of sugars by fungi. West Virginia Univ. Exp. Sta. Bul. 362 T. 58 p.

56. Lilly, V. G. 1963. The relation of fungus physiology to physiology of disease, p. 33-64. In The physiology of fungi and fungus diseases. West Virginia Univ. Exp. Sta. Bul. $488 \mathrm{~T}$.

57. Loo, Y. H., P. S. Skell, H. H. Thornberry, J. Ehrlich, J. M. McGuire, G. M. Savage, and G. M. Silvester. 1945. Assay of streptomycin by the paper-disc plate method. J. Bacteriol. 50: 701-709.

58. Miner, R. W. (ed.) 1954. Speciation and variation in asexual fungi. Ann. New York Acd. Sci. 60 (1): 1-182. 
59. Moat, A. G., N. Peters, and A. M. Srb. 1959. Selection and isolation of auxotropic yeast mutants with the aid of antibiotics. J. Bacteriol. 77: 673-677.

60. Owen, J. H., J. C. Walker, and M. A. Stahmann. 1950. Variability in onion neck-rot fungi. Phytopathology 40: 749-768.

61. Papavizas, G. C., and C. B. Davey. 1959. Evaluation of various media and antimicrobial agents for isolation of soil fungi. Soil Science. 88: $112-117$.

62. Parmeter, J. R., W. C. Snyder, and R. E. Reichle. 1963. Heterokaryosis and variability in plant pathogenic fungi. Ann. Rev. Phytopathol. 1: 51-76.

63. Paul, W. R. C. 1929. Strains of Botrytis cinerea Pers. Brit. Mycol. Soc., Trans. 14: 118-138.

64. Pontecorvo, G. 1949. Auxonographic techniques in biochemical genetics. J. Gen. Microbiol. 3: 122-126.

65. Pontecorvo, G., J. A. Roper, and E. Forbes. 1953. Genetic recombination without sexual reproduction in Aspergillus niger. J. Gen. Microbiol. 8: 198-210.

66. Pontecorvo, $\mathrm{G}_{2}$, and G. Sermonti. 1954. Parasexual recombination in Penicillium chrysogenum. J. Gen. Microbiol. 8: 198-210.

67. Pontecorvo, G. 1958. Trends in genetic analysis. Columbia Univ. Press. New York. $145 \mathrm{p}$.

68. Raut, C. 1953. A cytochrome mutant of Saccharomyces cerevisiae. Exp. Cell Res. 4:295-305.

69. Reddick, D., and W. R. Mills. 1938. Building up virulence in Phytophthora infestans. Am. Potato J. 15: 29-34.

70. Reed, G. M. 1946. Physiological specialization of the parasitic fungi. Bot. Rev. 12: 141-164.

71. Roberts, C. F. 1959. A replica planting technique for the isolation of nutritionally exacting mutants of a filamentous fungi (Aspergillus nidulans). J. Gen. Microbiol. 20: 540-548.

72. Schneider, I. R. 1956. A selective medium for the routine isolation of Graphium ulmi Schwarz. Plant. Dis. Reptr. 40: 816-821.

73. Siegel, M. R., and H. D. Sisler. 1964. Site of action of cycloheximide in cells of Saccharomyces pastorianus. Biochem. Biophys. Acta. 817: 70-82. 
74. Smale, B. C., and J. F. Worley. 1956. Evaluation of 2-3-5 triphenyl tetrazolium chloride for obtaining pathogenicity types from stock cultures of halo blight and common blight organisms. Plant Dis. Reptr. 40: 628 .

75. Smale, B. C., M. D. Montgillon, and T. G. Pridham. 1961. Phleomycin, an antibiotic markedly effective for control of bean rust. Plant Dis. Reptr. 45: 244-247.

76. Snyder, W. C., and H. N. Hansen. 1941. The effect of light on taxonomic characters in Fusarium. Mycologia 33: 580-591.

77. Snyder, W. C., and H. N. Hansen. 1954. Variation and speciation in the genus Fusarium. Vol. 60. p. 16-23. In R. W. Miner (ed.). 1954. Speciation and variation in asexual fungi. Ann. New York Acad. Sci. New York.

78. Snyder, W. C. 1959. Symposium on genetic approach to elucidation of mechanisms governing pathogenicity and disease resistance. Epilogue to part III. p. 215-218. In Plant Pathology: Problems and progress. 1908-1958. 1959. Univ. Wisconsin Press. Madison.

79. Squibb, E. R., and Sons. New York. 1961. Mycostatin sterile powder. 4 p.

80. Stakman, E. C., and J. J. Christensen. 1953. Problems of variability in fungi. p. 35-62. In Plant Diseases. U.S.D.A. Yearbook.

81. Stakman, E. C., and J. C. Harrar. 1957. Principles of plant pathology. Ronald Press Co. New York. 581 p.

82. Stevens, F. L. 1931. The fungi which cause plant diseases. The Macmillan Co. New York. 754 p.

83. Tatum, E. L., R. W. Barrat, and V. M. Cutter, Jr. 1949. Chemical induction of colonial paramorphs in Neurospora and Syncephalastrum. Science 109: 509-510.

84. Thanos, A. 1952. Effect of cycloheximide (Actidione) and some environmental factors on the germination of spores of Monilinia fructicola and Botrytis cinerea. Phytopathology 42: $2 \overline{1 \text { (Abstr.) }}$

85. Wallen, W. R., M. D. Sutton, and A. J. Skolko. 1950. The effect of actidione on the growth of certain pathogenic fungi and on germination of pea seed. Phytopathology 40: 156-160.

86. Ward, E. W. B., and A. W. Henry. 1961. Growth inhibition of two saprophytic and two plant parasitic soil fungi by antibiotics. Can. J. Bot. 39: 491-495.

87. Ward, H. M. 1903. Further observations on the brown rust of the Bromes. Puccinia dispersa (Eriks.) and its adaptative parasitism. Ann. Myco1. 1: 132-151. 
88. Warren, J. R., and N. N. Winstead. 1965. Chlorella as a possible test organism for biochemical studies of pathogenesis. Phytopathology 55: 244-245.

89. Wheeler, H. E., and S. J. P. Chilton. 1948. The occurrence of certain variants in the genus Glomerella. Louisiana Acad. Sci., Proc. 11: 30-31.

90. Wheeler, H. E. 1950. Genetics of Glomerella VIII. Genetic basis for the occurrence of minus mutants. Am. J. Bot. 37: 304-313.

91. Wheeler, H. E. 1952. Genetics of Glomerella X. Genes affecting sexual reproduction. Am. J. Bot. 39: 110-119.

92. Wilcox, L. V., Jr. 1960. The vitamin nutrition of Botrytis gladiolorum in relation to asexual reproduction. phytopathology 50: 241 (Abstr.)

93. Woodward, V. W., J. R. de Zeeuw, and A. M. Srb. 1954. The separation and isolation of particular biochemical mutants of Neurospora by differential germination of conidia, followed by filtration and selective plating. Nat. Acad. Sci., Proc. 40: 192-200. 


\section{BIOGRAPHICAL SKETCH}

Carlos Enrique Ampuero was born April 29, 1929 in Guayaquil, Ecuador. He graduated from Vicente Rocafuerte High School in January, 1948. He attended the University of Guayaquil, Ecuador, from May, 1949, until January, 1954. He started working at the Experimental Station of Pichilingue, Ecuador, in June, 1954 as a graduate assistant. In December, 1954, he received the Ingeniero Agronomo Degree from the University of Guayaquil. He was promoted to Assistant Plant Pathologist in September, 1957 and was granted a scholarship by the U.S. International Cooperation Administration to pursue graduate studies at the Interamerican Institute of Agriculture Sciences (O.E.A.), Turrialba, Costa Rica. He received the Magister Agriculturae Degree in December, 1958, majoring in Plant Pathology and resumed his position as Assistant Plant Pathologist at the Experimental Station of Pichilingue. In September, 1959, he was promoted to Head of Department, and, in February, 1960, to Station Director. A scholarship was provided by the U.S. Agency for International Development in August, 1962, which allowed hin to complete his graduate studies at the University of Florida. He was awarded the degree Doctor of Philosophy in August, 1965, with a major in Plant Pathology and minors in Botany and Agronomy. Carlos Enrique Ampuero is married to the former Dora Rodriguez Bowen and is father of two children. He is a member of the American Phytopathological Society, American Institute of Biological Sciences, Sociedad de Ingenieros Agrónomos del Ecuador, Alpha Zeta Honorary fraternity and Gamma Sigma Delta. 
This dissertation was prepared under the direction of the chairman of the candidate's supervisory committee and has been approved by all members of that committee. It was submitted to the Dean of the College of Agriculture and to the Graduate Council, and was approved as partial fulfillment of the requirements for the degree of Doctor of Philosophy.

August, 1965

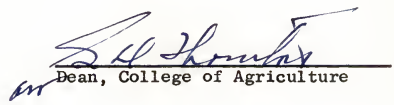

Dean, Graduate School

Supervisory Committee:

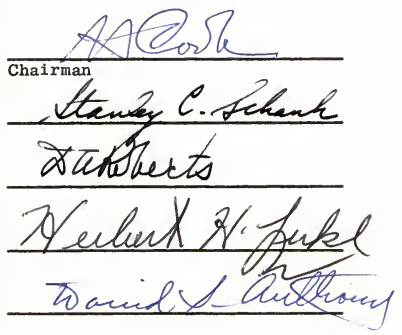

